\title{
Yüksek İç Fazlı Emülsiyon Kalıplama ile Metakrilat Esaslı Küresel Polimerlerin Hazırlanması
}

\author{
Funda ÇíRA ${ }^{3}$, E. Hilal MERT ${ }^{2}$, Burcu KEKEVI $^{1 *}$ \\ Geliş / Received: 08/01/20 \\ Revize / Revised: 07/05/2020 \\ Kabul / Accepted: 07/05/2020
}

\section{ÖZ}

Epoksi fonksiyonel gruplara sahip gözenekli polimer küreleri, glisidil metakrilat (GMA) ile esnek gruplara sahip 1,3-bütandiol dimetakrilat (BDDMA) karışımından oluşan monomer bileşimi içinde sulu iç faz çözeltisinin dağıtılması ile elde edilen öncü konsantre emülsiyon kalıpları kullanılarak sentezlendi. Bu amaçla, sulu pullulan çözeltilerinin iç faz olarak kullanılması ile GMA ve BDDMA’nın yüksek iç fazlı emülsiyonları (high internal phase emulsions, HIPEs) hazırlandı. Polimerleştirme adımı, öncü HIPE'lerin sekonder bir sulu ortamda dağıtılması ile elde edilen su/yağ/su (w/o/w) sistemleri içerisinde gerçekleştirildi. Öncü emülsiyon kalıplarının hazırlanmasında farklı konsantrasyonlardaki pullulan çözeltileri iç faz olarak kullanılarak, her bir bağımsız polimer fazın veya ağın kendi özelliklerini koruduğu ve birbirleri ile sinerjik bir etkileşim içinde olduğu yarıgeçişimli bir polimerik ağ yapısı elde edildi. Elde edilen polimer (poliHIPE) kürelerinin morfolojik özellikleri mikroskobik görüntüleme teknikleri ile incelendi. Spesifik yüzey alanları ise elde edilen kürelerin $\mathrm{N}_{2}$ adsorpsiyon/desorpsiyon izotermlerine Brunauer-Emmett-Teller (BET) denklemi uygulanarak hesaplandi.

\footnotetext{
1*Sorumlu yazar iletişim: bkekevi@yalova.edu.tr (https://orcid.org/0000-0002-2364-1957)

Malzeme ve Malzeme Isşleme Teknolojileri Bölümü, Yalova Üniversitesi, Yalova Meslek Yüksekokulu, Yalova

2İletişim: hmert@yalova.edu.tr (https://orcid.org/0000-0003-4267-7469)

Polimer ve Malzeme Mühendisliği Bölümü, Mühendislik Fakültesi, Yalova Üniversitesi, Yalova

3̇letişim: funda.cira.89@gmail.com (https://orcid.org/0000-0001-7694-2051)

Polimer ve Malzeme Mühendisliği Bölümü, Mühendislik Fakültesi, Yalova Üniversitesi, Yalova
} 


\title{
Preparation of Methacrylate Based Spherical Polymers via High Internal Phase Emulsion Templating
}

\begin{abstract}
Epoxy functional spherical polymer beads were synthesized by using precursor concentrated emulsions templates obtained by dispersing aqueous internal phase solution in the monomer mixture composed of glycidyl methacrylate (GMA) and 1,3-butandiol dimethacrylate having flexible groups. For this purpose, high internal phase emulsions (HIPEs) of GMA and BDDMA were obtained with the use of aqueous pullulan solutions as the internal phase. Polymerization step was achieved within the water/oil/water $(\mathrm{w} / \mathrm{o} / \mathrm{w})$ systems that were prepared by dispersing precursor HIPEs in a secondary aqueous medium. On the other hand, by using aqueous pullulan solutions during the preparation of precursor emulsion templates, a semi-interpenetrating polymer network structure in which each individual phase or network retains their individual properties and causes synergistic interaction, was obtained. The morphological properties of the resulting polymer (polyHIPE) beads were investigated by using microscopic imaging techniques. The specific surface areas were calculated by applying Brunauer-Emmett-Teller (BET) equation to the $\mathrm{N}_{2}$ adsorption/desertion isotherms of the resulting beads.
\end{abstract}

Keywords- Emulsion templating, High internal phase emulsion, polyHIPE beads 


\section{GIRIŞ}

Yüksek iç fazlı emülsiyonlar (High Internal Phase Emulsion, HIPEs) iç faz hacmi toplam emülsiyon hacminin en az \%74'ünü oluşturan konsantre emülsiyon sistemleridir. Bu oran düzgün, deforme olmamış küresel partiküller tarafından işgal edilen ve en etkin şekilde paketlenmenin gerçekleştiği maksimum hacmi temsil etmekle birlikte \%99' a kadar çıkarılabilmektedir [1]. Bu tür emülsiyonların hazırlanabilmesi için birisi genellikle su (veya sulu çözelti) olan ve birbiri ile karışmayan iki sıvı faz gereklidir. HIPE'ler, uygun emülgatör(ler) varlığında dispers fazın sürekli faz içerisinde damlalar halinde dağıtılması yoluyla yağ-içinde-su (water-in-oil, w/o), ya da tam tersi yani su-içinde-yağ (oil-in-water, o/w) şeklinde hazırlanabilir [2]. Sürekli fazın monomer(ler) içermesi durumunda, HIPE'lerin uygun koşullar altında polimerleştirilmesi ve ardından dispers fazın uzaklaştırılması ile boşlukların etrafını saran sürekli bir polimer filmi oluşturulabilir. Elde edilen ağ yapılı bu polimerler ise yüksek gözenekliliğe sahip olup, açık hücresel bir morfoloji sergilerler. HIPE kalıplama yöntemi olarak tanımlanan bu yaklaşım, morfolojileri büyük ölçüde kontrol edilebilir polimerlerin hazırlanmasına olanak sağladığından, açık hücresel yapılı polimerlerin hazırlanmasında kullanılan diğer tüm yaklaşımlara kıyasla daha fazla öne çıkmaktadır [3-5]. Bununla birlikte, bu yaklaşımın kullanılması ile hazırlanan polimerler literatürde poliHIPE olarak adlandırılmakta ve böylece gözeneklilik oluşturma yöntemleri ile sentezlenen diğer açık hücresel yapılı polimerlerden de ayrılmaktadır [1-6].

PoliHIPE'ler iki düzeyli ve oldukça özel bir gözenek morfolojisine sahiptir. Küresel yapılı gözeneklerde birinci düzeyi daha büyük olan hücreler (veya boşluklar) (çapları genellikle 1-100 $\mu \mathrm{m}$ ), ikinci düzeyi ise hücreleri birbirine bağlayan daha küçük boyutlu gözenek geçitleri (veya pencereler) oluşturur. Bu nedenle açık hücresel yapı sergileyen bu özel polimerlerde hiyerarşik gözenek dağılımı mevcuttur ve bu malzemeler oldukça düşük yoğunlukludur. PoliHIPE’lerde, küresel gözeneklerin çapları öncü HIPE kalıplarının damla boyutları ile neredeyse aynıdır. Bu durum sürekli fazdan polimer jel fazının ayrılma termodinamiği ile emülsiyon faz ayrılması yoluyla damlacık stabilizasyonu arasındaki mükemmel denge ile yönetilmektedir [7,8]. Genel olarak, poliHIPE'lerin morfolojik, mekanik ve diğer fiziksel özellikleri kullanılan öncü HIPE'lerin hazırlanması sırasında seçilen deneysel parametrelere (ör. faz oranları, karıştırma hızı, emülgatör oranı) bağlı olarak değişir [9].

PoliHIPE'ler özgün fiziksel özellikleri ile birlikte karmaşık prosesler ve yüksek maliyetler içermeyen hazırlama koşulları nedeniyle enerji ve gaz depolama [10-12], iyon değişimi [13-17], adsorpsiyon [18,19], kataliz [20-22] ve fotokataliz [23], enzim immobilizasyonu [24,25], proteinlerin saflaştırılması [26], doku mühendisliği [27-28], 1sıl enerji depolama [29] ve daha birçok uygulama oldukça geniş bir kullanım alanına sahiptir [3,4]. Bununla birlikte, poliHIPE'ler, HIPE'lerin uygun kalıplarda polimerleştirilmesi ile elde edildiğinden hedeflenen uygulama alanına yönelik olarak belirlenen boyutlarda ve formlarda hazırlanabilmektedir. Bu kapsamda emülsiyonların kalıplar içerisinde direkt polimerleştirilmesi ile monolitler elde edilirken, film hazırlama teknikleri kullanılarak belirli kalınlıktaki polimerik membranlar veya filmler elde edilebilmektedir [3-5]. Ayrıca, öncü HIPE'lerin uygun bileşimdeki sekonder bir sulu ortamda kontrollü olarak damlalar halinde dağıtılmasının ardından polimerleştirilmesi yoluyla küresel şekilli poliHIPE'ler de hazırlanabilmektedir [17,30]. PoliHIPE'lerin geliştirilmesi amacıyla literatürde yapılan çalışmaların önemli bir kısmı yüksek gözenekli yapının neden olduğu zayıf mekanik özelliklerin geliştirilmesi üzerine yoğunlaşmaktadır. Bu noktada, kullanılan farklı yaklaşımların poliHIPE’lerin gözenek morfolojisi ve mekanik özelliklerine etkisi araştırılmaktadır [9,19,23,31]. PoliHIPE'leri konu alan diğer çalışmalar ise büyük çoğunlukla gözenekli yapıları nedeniyle adsorpsiyon kapasitesi yüksek olan bu polimerlerin çeşitli kirleticilerin giderilmesindeki rolünün araştırılması üzerine yoğunlaşmaktadır [14-19,23,32].

Bu çalışmada ise biyolojik uygulamalarda (özellikle enzim immobilizasyonu ve protein saflaştırma gibi) kullanım potansiyeli olan, fonksiyonlandırma işlemleri için müsait gruplar taşıyan küresel polimer kompozitleri (poliHIPE küreleri) emülsiyon kalıplama yöntemi kullanılarak sentezlenmiştir. Küresel poliHIPE'lerin sentezinde kullanılan öncü HIPE'lerin sürekli fazı fonksiyonlandırmaya uygun epoksi halkasına sahip glisidil metakrilat (GMA) monomeri ile yapıya esneklik katan 1,3-bütandiol dimetakrilat (BDDMA) monomeri kullanılarak hazırlanmıştır. İç faz olarak ise, suda çözünebilen bir polisakkarit olan pullulanın farklı konsantrasyonlardaki sulu çözeltileri kullanılmıştır. Pullulan; toksik olmaması, çevreci yönü, çeşitli yağlara karşı kimyasal dayanım göstermesi, biyo-indirgen özelliği ile birlikte şeffaf, renksiz ve kokusuz oluşu ile de dikkat çeken doğal kaynaklı bir polimerdir. Bu özellikler sebebiyle de ısıl ve mekanik etkilere karşı dayanım gösteren 
ve oksijen bariyeri özelliğine sahip filmlerin hazırlanmasında yaygın olarak kullanılır. Bunlara ek olarak, suda çözünerek viskoz ve berrak çözeltiler oluşturmasına rağmen metanol, aseton ve etanol gibi solventlerde çözünmemesi de uygulamalar açısından önemli bir avantaj yaratır. Dahası, polimer matrislerinin pullulan ile birleştirilmesi malzemelerin mekanik dayanımlarının belirgin bir şekilde geliştirilmesine katkı sağlar [33,34]. Bu çalışma ile HIPE kalıplarında iç faz olarak pullulan çözeltilerinin kullanılması yoluyla ilk kez küresel formdaki yarı-geçişimli polimerik ă̆ yapıları elde edilmiştir ve bu özel yapının elde edilen poliHIPE kürelerinin morfolojisi üzerindeki etkileri ayrıntılı olarak incelenmiştir.

\section{MALZEMELER VE YÖNTEM}

Küresel poliHIPE'lerin sentezlenmesinde kullanılan glisidil metakrilat (GMA, \%97, Aldrich), 1,3bütandiol dimetakrilat (BDDMA, \%98, Aldrich), Pluronic L121 (poli(etilen glikol)-blok-poli(propilen glikol)blok-poli(etilen glikol), $\overline{\mathrm{M}}_{\mathrm{w}}: 4400$, Aldrich), pullulan ( $\overline{\mathrm{M}}_{\mathrm{w}}: 100000$, Fluka), etanol (teknik), hidroksi etil selüloz (HEC, Aldrich), kalsiyum fosfat $\left(\mathrm{CaPO}_{4}\right.$, Riedel de Haen) ve potasyum persülfat (KPS, Merck) herhangi bir saflaştırma işlemi yapılmadan kullanıldı. 2,2'-Azobisizobütironitril (AIBN, Merck) ise, etanolden kristallendirilerek kullanıldı. Gerçekleştirilen tüm denemelerde ultrasaf deiyonize su vakum altında degaz edildikten sonra kullanıldı.

PoliHIPE kürelerinin morfolojisi FEI-Philips XL30 ESEM-FEG (Philips, Eindhoven, The Netherlands) model Taramalı Elektron Mikroskobu (Scanning Electron Microscope, SEM) kullanılarak incelendi. Bu amaçla elde edilen poliHIPE küreleri metal ayaklar üzerine tutturulduktan sonra vakum altında altın ile iletken hale getirildi.

PoliHIPE kürelerinin partikül şekli ve boyutu Olympus System Metallurgical BX51M Microscope (Olympus Soft Imaging Solutions GmbH \& Co.KG, Germany) Polarize Optik Mikroskop (POM) kullanılarak incelendi. Bu amaçla temiz bir lam üzerine sabitlenen örneklerin 5x büyütme ile POM görüntüleri kaydedildi. Kaydedilen görüntüler ortalama partikül boyutlarının ve boyut dağılımlarının hesaplanmasında kullanıldı. Bu amaçla, her numune için POM görüntüsünden en az 50 tane küresel poliHIPE partikülünün çapı ölçülerek aritmetik ortalaması ve standart sapması hesaplandı. Elde edilen sonuçlar kullanılarak küresel poliHIPE'lerin istatiksel boyut dağılımları elde edildi.

PoliHIPE kürelerinin spesifik yüzey alanı Micromeritics Gemini VII 2390t Overall Automatic BET Surface Area and Pore Size Analyzer (Micromeritics Instrument Corporation, USA) cihazında kaydedilen $\mathrm{N}_{2}$ adsorpsiyon/desoprsiyon izotermlerine BET denklemi uygulanarak hesaplandi. Numuneler analize Micromeritics Flow Prep 060 Sample Degas System (Micromeritics Instrument Corporation, USA) degaz istasyonunda 24 sa süreyle $80^{\circ} \mathrm{C}$ 'de degaz edilerek hazırlandı.

\section{A. HIPE hazırlama}

Küresel poliHIPE sentezinde kullanılan öncü HIPE’ler literatürde yer alan referans çalışmamız temel alınarak toplam emülsiyon hacmine göre \%75 oranında iç faz kullanılarak hazırlandı [30]. Bu amaçla GMA (toplam monomer hacmine göre \%90 oranında) ve BDDMA (toplam monomer hacmine göre \%10 oranında) kullanıldı. HIPE'lerin sürekli fazı monomerlerin, emülgatörün (Pluronic L 121; \%30 sürekli faz hacmine göre) ve başlatıcının (AIBN; \%1 monomerlerin mol sayısına göre) yuvarlak dipli bir cam reaktörde karıştırılması ile elde edildi. Ardından sullu pullan çözeltisi (ağırlıkça \%1, 3 veya 5 oranında pullulan ile hazırlanan) peristaltik pompa ile sabit karıştırma eşliğinde (300 rpm) sürekli faza eklendi. Pullulan çözelitisinin eklenmesinin ardından elde edilen krem benzeri öncü emülsiyonlar 15 dak daha sabit hızla karıştırıldı.

Emülsiyon bileşimine pullulan eklenmesinin elde edilen poliHIPE kürelerinin morfolojisi üzerindeki etkilerinin belirlenebilmesi amacıyla referans numune olarak pullulan içermeyen GMA/BDDMA öncü HIPE'leri de hazırlandı. Bu amaçla yukarıda açıklanan prosedür, iç faz olarak pullulan çözeltisi yerine ultrasaf deiyonize su kullanılarak uygulandı. 


\section{B. Küresel poliHIPE sentezi}

Küresel poliHIPE'ler $80^{\circ} \mathrm{C}$ 'de sabitlenen çift cidarlı ve iki boyunlu cam reaktör sistemi içinde sentezlendi. Bu amaçla, öncü HIPE'ler polimerik bir stabilizatör, suda çözünen bir başlatıcı ve koruyucu kolloid içeren reaktör sistemine peristaltik pompa yardımı ile damlalar halinde gönderildi. Böylece polimerleştirme işlemi su-yağ-su (w/o/w) türündeki çift emülsiyon sistemleri içinde gerçekleştirildi [17]. Örnek bir denemede; hazırlanan öncü GMA/BDDMA/pullulan veya GMA/BDDMA HIPE'leri, deiyonize su (500 g), başlatıcı (KPS, ağırlıkça \%0.1 oranında), $\mathrm{CaPO}_{4}$ (ağırlıkça \%0.1 oranında), suda çözünen polimerik stabilizatör (HEC veya pullulan; ağırlıkça \%0.2, 0.6, veya 1.0 oranında) içeren reaktör ortamına sabit hızla karıştırma (200 rpm) eşliğinde damlalar halinde ( $50 \mathrm{rpm}$ besleme hızı ile) eklendi ve 24 sa boyunca sabit hızla karıştırılarak çapraz bağlanma reaksiyonu gerçekleştirildi. Ardından elde edilen küreler süzüldü, etanol ile yıkandı ve $50^{\circ} \mathrm{C}$ 'deki vakum etüvünde kurutuldu.

\section{BULGULAR}

Küresel poliHIPE'ler, hazırlanan öncü HIPE'lerin $80^{\circ} \mathrm{C}$ 'deki sekonder sisteme sabit karıştırma eşliğinde ve damlalar halinde eklenmesinin ardından elde edilen w/o/w sistemleri içerisinde çapraz bağlanması ile sentezlendi. Bu kapsamda öncelikle sekonder sulu ortamda kullanılan stabilizatörün küresel polimer yapısının oluşumuna etkisi araştırıldı. Bu çerçevede yapılan denemelerde öncü HIPE kalıbı olarak pullulan içermeyen GMA/BDDMA HIPE'leri kullanıldı. Gerçekleştirilen çalışmalarda öncelikle stabilizatör olarak HEC kullanılarak denemeler yapıldı. Ardından fiziksel özellikleri ve kimyasal yapısı nedeniyle pullulanın da benzer bir etki gösterebileceği göz önünde bulunduralarak sekonder sulu ortamda stabilizatör olarak pullulan kullanılarak polimer sentezi gerçekleştirildi. Elde edilen küresel poliHIPE’lerin morfolojik yapıları POM ve SEM görüntüleri kullanılarak araştırıldı ve elde edilen görüntüler Şekil 1 ve 2’de sunuldu.

Şekil 1'de sunulan POM (sol sütun) ve SEM (sağ sütun) görüntülerinin incelenmesi sonucunda öncü HIPE damlalarının stabilizasyonunu sağlamak amacıyla kullanılan HEC miktarının partikül aglomerasyonunun önlenmesi yönünden oldukça önemli olduğu belirlendi. Buna göre, HEC konsantrasyonu ile partiküllerin aglomerasyon yönelimi arasında ters orantı olduğu gözlemlendi. Buna rağmen partikül boyutunun HEC konsantrasyonu ile doğru orantılı olarak arttığı saptandı. Sentezlenen poli(GMA-ko-BDDMA) poliHIPE kürelerinin POM görüntülerinden yola çıkılarak hesaplanan boyut dağılımlarına göre: \%1.0 oranında HEC ile stabilize edilen ortamda hazırlanan partiküllerinin yaklaşık olarak \%5'inin 200-250 $\mu$ m, \%13'ünün 150-200 $\mu \mathrm{m}, \% 49$ 'unun 100-150 $\mu \mathrm{m}, \% 25$ 'inin ise 50-100 $\mu \mathrm{m}$; \%0.6 oranında HEC kullanılarak stabilize edilen ortamda

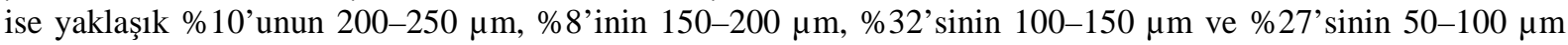
aralığında değişen boyutlara sahip olduğu belirlendi. HEC oranı $\% 0.2$ olduğunda ise partikül boyutlarının \%4'ünün 200-250 $\mu \mathrm{m}$, \%11'inin 150-200 $\mu \mathrm{m}$, \%40'ının 100-150 $\mu \mathrm{m}$ ve \%41'inin 50-100 $\mu \mathrm{m}$ aralığında değiştiği saptandi.

Stabilizatör olarak pullulan kullanılması ile sentezlenen poliHIPE kürelerinin Şekil 2'de sunulan POM (sol sütun) ve SEM (sağ sütun) görüntüleri incelendiğinde ise pullulan konsantrasyonu ile hem partiküllerin aglomerasyon yöneliminin hem de partikül boyutunun ters orantılı olarak değiştiği saptandı. Bununla birlikte, sekonder sulu ortamda pullulan kullanılmasının malzemelerin kırılganlığını ve yüzey pürüzlülüğünü de $\operatorname{arttırdığı~}$ gözlemlendi. Sentezlenen küresel yapıdaki poli(GMA-ko-BDDMA) poliHIPE'lerinin POM görüntüleri kullanılarak hesaplanan ortalama partikül boyutlarının değerlendirilmesi sonucunda ise \%1.0 oranında pullulan kullanılarak stabilize edilen ortamda sentezlenen kürelerin yaklaşık olarak \%19'unun 150-200 $\mu \mathrm{m}$, \%52'sinin

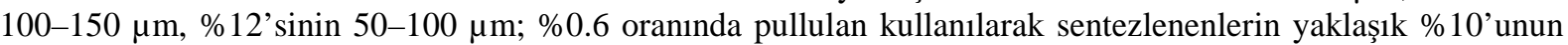
150-200 $\mu \mathrm{m}$, \%43'ünün 100-150 $\mu \mathrm{m}$ ve $\% 32$ 'sinin $50-100 \mu \mathrm{m} ; \% 0.2$ oranında pullulan ile stabilize edilen ortamda sentezlenen partiküllerin ise yaklaşık \%11'inin 150-200 $\mu \mathrm{m}, \% 48$ 'inin 100-150 $\mu \mathrm{m}$ ve \%28'inin 50$100 \mu \mathrm{m}$ aralığında değişen boyutlara sahip olduğu belirlendi.

HEC veya pullulan ile kararlı kılınan sistemler üzerinden sentezlenen küresel yapıdaki poli(GMA-koBDDMA) poliHIPE'lerinin BET metodu ile ölçülen spesifik yüzey alanları ( $S_{\text {BET }}$ ) Tablo 1'de sunuldu. Tablo 1 'de sunulan bulguların incelenmesi sonucunda, elde edilen poliHIPE kürelerinin spesifik yüzey alanlarının, kullanılan stabilizatörün türüne bağlı olmaksızın artan stabilizatör miktarı ile ters orantılı olarak değiştiği 


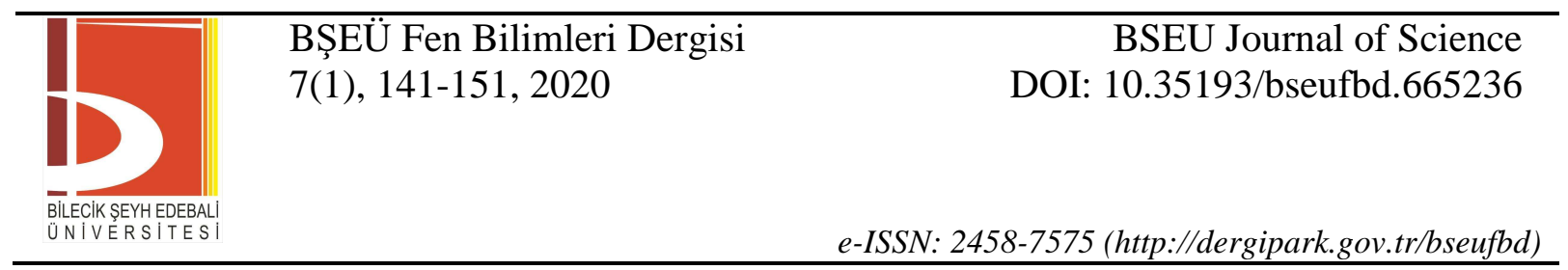

belirlendi. Bu durum, ortamda yüksek konsantrasyonlarda çözünmüş olarak bulunan polimerik stabilizatörün topaklanma eğilimine bağlı olarak açıklanabilmektedir.

Tablo 1. HEC veya pullulan ile stabilize edilen ortamlarda sentezlenen poli(GMA-ko-BDDMA) poliHIPE kürelerinin spesifik yüzey alanı.

\begin{tabular}{ccc}
\hline Stabilizatör & $\begin{array}{c}\text { Stabilizatör Oranı } \\
(\% \text { Ăgırlık })\end{array}$ & $\begin{array}{c}\mathbf{S}_{\text {BET }} \\
\left(\mathbf{m}^{\mathbf{2}} \mathbf{g}^{\mathbf{1}} \mathbf{)}\right.\end{array}$ \\
\hline HEC & 0.2 & 8.59 \\
HEC & 0.6 & 5.76 \\
HEC & 1.0 & 3.41 \\
Pullulan & 0.2 & 9.47 \\
Pullulan & 0.6 & 6.07 \\
Pullulan & 1.0 & 7.80 \\
\hline
\end{tabular}
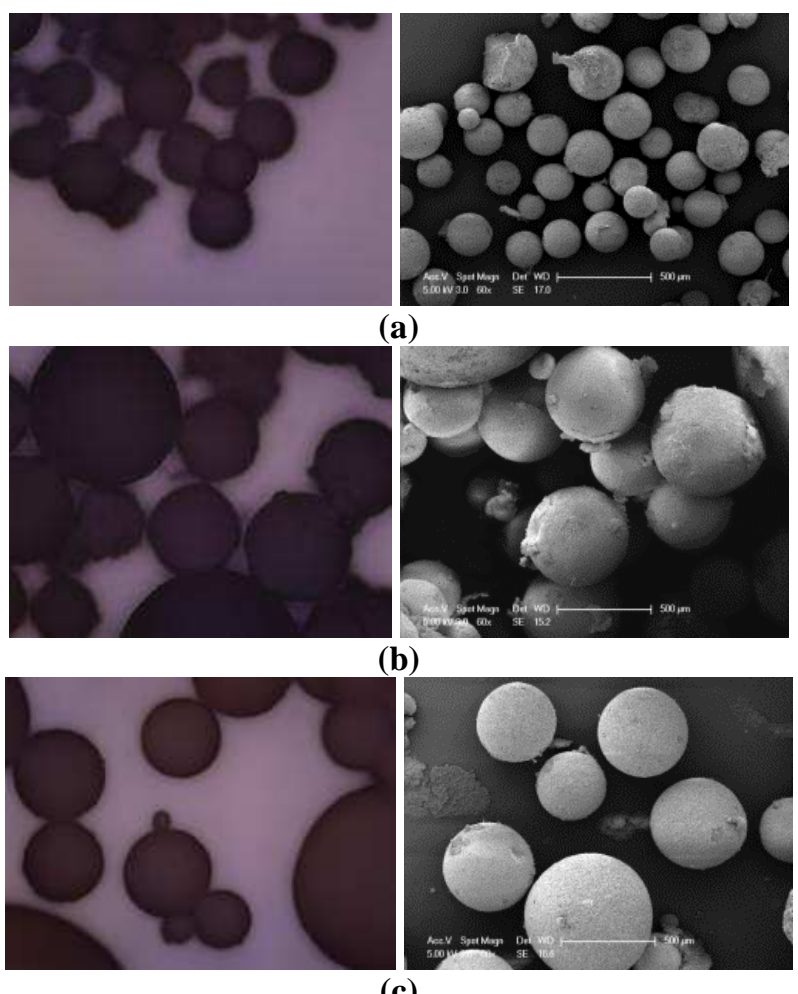

(c)

Şekil 1. (a) $\% 0.2$, (b) $\% 0.6$ ve (c) $\% 1.0$ oranında HEC ile stabilize edilen ortamda sentezlenen poliHIPE kürelerinin POM (sol sütun) ve SEM görüntüleri (sağ sütun - skala: $500 \mu \mathrm{m}$ ). 


\begin{tabular}{|c|c|c|}
\hline & $\begin{array}{l}\text { BŞEÜ Fen Bilimleri Dergisi } \\
7(1), 141-151,2020\end{array}$ & $\begin{array}{r}\text { BSEU Journal of Science } \\
\text { DOI: } 10.35193 / \text { bseufbd.665236 }\end{array}$ \\
\hline ERS & & 58-7575 (http://dergipark.gov.tr/bseufbd) \\
\hline
\end{tabular}

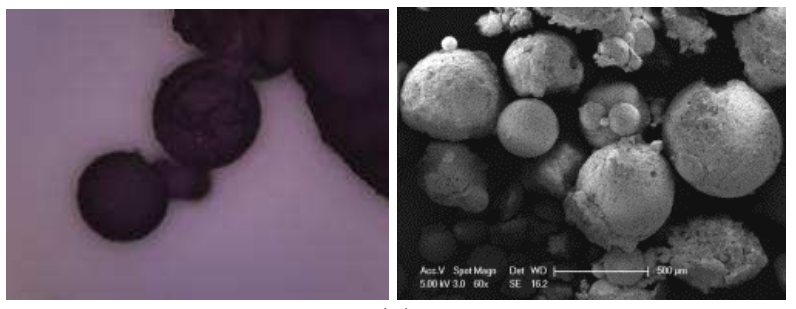

(a)
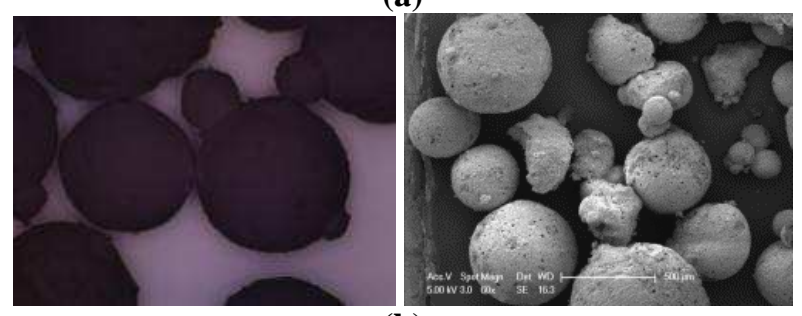

(b)

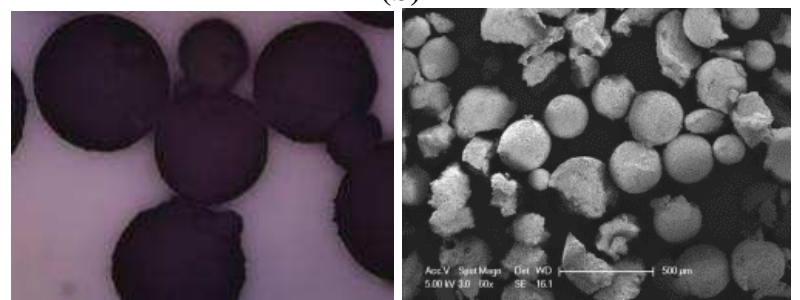

(c)

Şekil 2. (a) \%0.2, (b) \%0.6 ve (c) \%1.0 oranında pullulan ile stabilize edilen ortamda sentezlenen poliHIPE kürelerinin POM (sol sütun) ve SEM görüntüleri (sağ sütun - skala: $500 \mu \mathrm{m}$ ).

Öncü HIPE'lerin sürekli fazının pullulan ile birleştirilmesinin sentezlenen küresel poliHIPE'lerin morfolojik özellikleri üzerindeki etkileri, ağırlıkça \%1 oranında HEC veya pullulan ile stabilize edilen sekonder sulu ortamda polimerleştirilmeleri yoluyla elde edilen yarı-geçişimli ă̆ yapıdaki küresel poli(GMA-koBDMMA)/pullulan kompozitlerinin morfolojik özelliklerinin incelenmesi yoluyla aydınlatıldı. Bu amaçla, sentezlenen poliHIPE kompozitlerinin morfolojik özellikleri SEM ile incelendi. SEM görüntüleri üzerinden yapılan inceleme sonucunda küresel partiküllerin sentezinde kullanılan öncü HIPE sistemlerinin pullulan ile birleştirilmesi ile elde edilen kürelerin morfolojik özelliklerinin dikkat çekici bir şekilde değiştiği gözlemlendi. Şekil 3'de sunulan ve pullulan kullanılarak hazırlanan öncü HIPE'lerin HEC ile stabilize edilen ortamda polimerleştirilmesi ile elde edilen poli(GMA-ko-BDDMA)/pullulan yapılı küresel poliHIPE kompozitlerinin SEM görüntüleri incelendiğinde, küre yapısının artan pullulan konsantrasyonunun bir sonucu olarak belirgin bir şekilde deforme olduğu belirlendi. Bununla birlikte elde edilen küresel poliHIPE partiküllerinin Tablo 2'de sunulan spesifik yüzey alanlarının karşılaş̧ırılması sonucunda, bileşiminde \%1 oranında pullulan bulunan öncü HIPE'lerden elde edilen küresel kompozitlerin spesifik yüzey alanının pullulan içermeyen örneklere kıyasla 2.5 kat daha yüksek olduğu tespit edildi. Buna rağmen, öncü HIPE bileşiminde kullanılan pullulan miktarı ile elde edilen küresel poliHIPE kompozitlerinin spesifik yüzey alanının ters orantılı olarak değiştiği saptandı. Bu durum, öncü emülsiyonlardaki pullulan miktarının arttması ile HEC ve pullulan arasındaki etkileşimin artması ve bunun sonucunda ortamında çözünmüş olarak bulunan HEC'in topaklaşmasına bağlı olarak kolloidal kararlılığın azalması ve HIPE damlalarının aglomere olması ile açıklanabilir. Kolloidal kararlılıktaki azalmaya bağlı olarak elde edilen poliHIPE'lerin partikül şekil ve boyutunda ortaya çıkan deformasyon Şekil 3'de sunulan SEM görüntülerinde de açıkça görülmektedir.

Stabilizatör olarak dağıtıcı ortamda $\% 1.0$ oranında pullulan kullanılması yoluyla sentezlenen poliHIPE kürelerinin Şekil 4'de sunulan SEM görüntüleri incelendiğinde ise, öncü HIPE'lerde farklı oranlarda pullulan kullanılmasının partikül şekli üzerinde belirgin bir etkisinin olmadığı ancak partikül boyutlarının artmasına neden olduğu belirlendi. Bununla birlikte Tablo 2'de sunulan spesifik yüzey alanı değerleri karşılaştırıldığında, 


\begin{tabular}{|c|c|c|}
\hline & $\begin{array}{l}\text { BŞEÜ Fen Bilimleri Dergisi } \\
7(1), 141-151,2020\end{array}$ & $\begin{array}{r}\text { BSEU Journal of Science } \\
\text { DOI: } 10.35193 / \text { bseufbd.665236 }\end{array}$ \\
\hline $\begin{array}{l}\text { BLLECEKSEYHEDEBAL } \\
\text { UNIVERSITESI }\end{array}$ & & 58-7575 (http://dergipark.gov.tr/bseufbd) \\
\hline
\end{tabular}

$\% 1$ oranında pullulan içeren poliHIPE kürelerinin spesifik yüzey alanının pullulan kullanılmadan hazırlanan öncü HIPE'den elde edilen poliHIPE'lerle karşılaştırıldığında hafifçe azaldığı, bununla birlikte öncü HIPE bileşimindeki pullulan miktarının artmasının spesifik yüzey alanlarında önemli bir değişime neden olmadığı saptand..

Tablo 2. Stabilizatör olarak \%1.0 oranında HEC veya pullulan kullanılarak hazırlanan poli(GMA-ko-BDDMA)/pullulan poliHIPE kürelerinin spesifik yüzey alanı.

\begin{tabular}{ccc}
\hline Stabilizatör & $\begin{array}{c}\text { Öncï HIPE'nin Pullulan Oranı } \\
(\% \text { A ğırlı) }\end{array}$ & $\begin{array}{c}\mathbf{S}_{\text {BET }} \\
\left(\mathbf{m}^{\mathbf{2}} \mathbf{g}^{\mathbf{1}}\right)\end{array}$ \\
\hline HEC & 0 & 3.41 \\
HEC & 1 & 8.57 \\
HEC & 3 & 7.70 \\
HEC & 5 & 6.12 \\
Pullulan & 0 & 7.80 \\
Pullulan & 1 & 6.00 \\
Pullulan & 3 & 6.62 \\
Pullulan & 5 & 6.34 \\
\hline
\end{tabular}

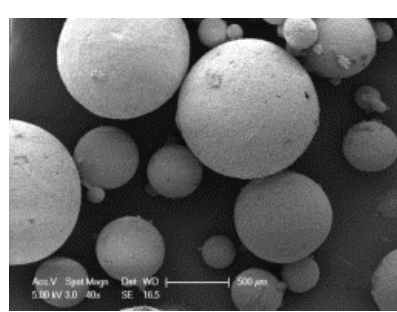

(a)

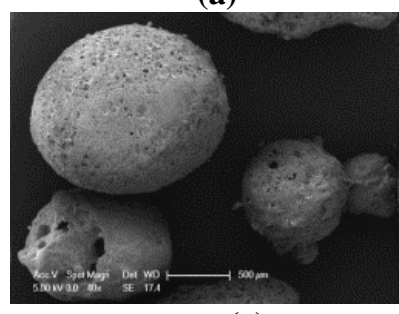

(c)

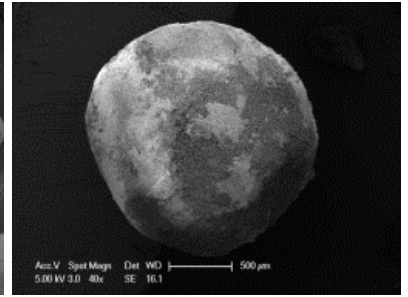

(b)

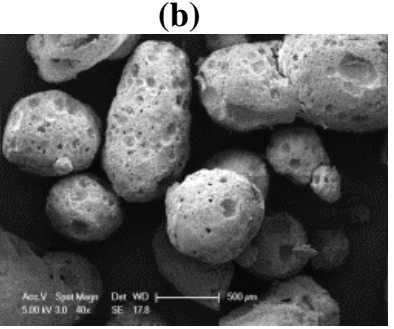

(d)

Şekil 3. \%1.0 oranında HEC stabilizatörü kullanılarak sentezlenen poli(GMA-ko-BDDMA)/pullulan poliHIPE kürelerinin SEM görüntüsü: öncü HIPE bileşiminde ağırlıkça (a) \%0, (b) \%1, (c) \%3 ve (d) $\% 5$ oranında pullulan kullanılarak sentezlenen polimer partikülleri (skala: 500 $\mu \mathrm{m})$. 


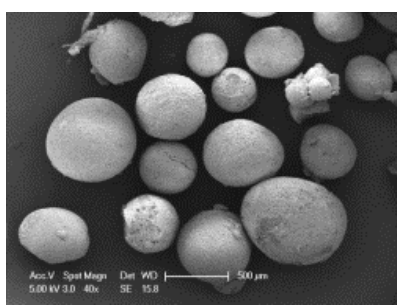

(a)

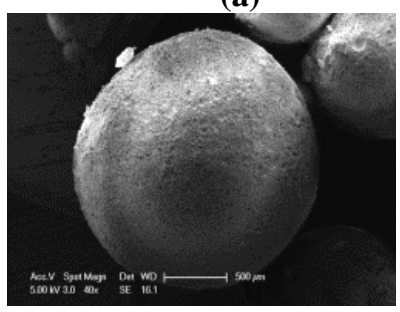

(c)

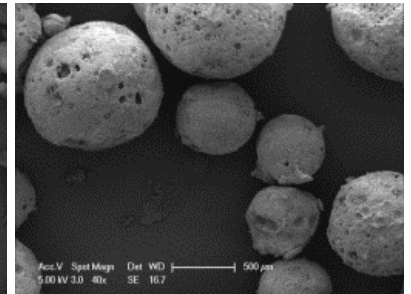

(b)

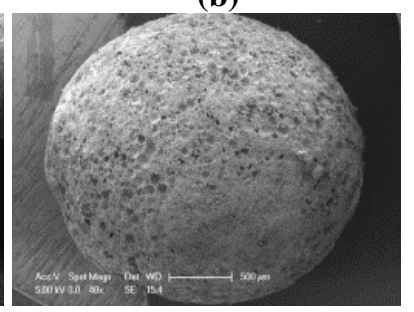

(d)

Şekil 4. \%1.0 oranında pullulan stabilizatörü kullanılarak sentezlenen poli(GMA-ko-BDDMA)/pullulan poliHIPE kürelerinin SEM görüntüsü: öncü HIPE bileşiminde ağırlıkça (a) \%0, (b) \%1, (c) \%3 ve (d) \%5 oranında pullulan kullanılarak sentezlenen polimer partikülleri (skala: $500 \mu \mathrm{m}$ ).

\section{TARTIŞMA VE SONUÇ}

PoliHIPE’ler özgün gözenek morfolojilerinin sağladığı avantajlardan dolayı pek çok farklı alanda kullanım potansiyeli olan malzemelerdir ve fonksiyonlandırmaya uygun kimyasal gruplar içeren poliHIPE'lerin sentezi oldukça önem taşımaktadır. Bu noktada GMA, reaktif epoksi gruplarının varlığı nedeniyle fonksiyonel poliHIPE sentezinde tercih edilen bir monomerdir. Ancak GMA'nın polar yapısı kararlı emülsiyonların hazırlanmasını güçleştirmektedir. Bu durum özellikle sekonder bir sulu sistem içinde öncü HIPE'lerin damlalar halinde dağıtılarak polimerleştirilmesi yoluyla poliHIPE kürelerinin hazırlanmasında büyük bir dezavantaj yaratmaktadır. Ayrıca poliHIPE'lerin, yüksek gözeneklilik sebebiyle oldukça zayıf olan mekanik dayanımları da uygulama özellikleri açısından büyük bir sorun oluşturmaktadır. Geçekleştirilen bu çalışmada, polimer matrise kazandırdığı kimyasal fonksiyonalite sebebiyle GMA monomer ve yapıya esneklik kazandıran grupları sayesinde polimer matrisin kırılganlığını azaltan BDDMA ise çapraz bağlayıcı komonomer olarak kullanılmıştır. Her ikisi de hidrofilik karaktere sahip bu iki monomer ile ortam polaritesinin emülsiyon kararlılığı üzerindeki olumsuz etkisine rağmen poliHIPE küreleri başarıyla sentezlenmiştir. Bununla birlikte, lineer bir homopolisakkarit olan pullulanın farklı konsantrasyonlardaki sulu çözeltilerinin iç faz olarak kullanılması ile literatürde ilk kez yarı-geçişimli ağ yapıda poliHIPE kürelerinin sentezi de gerçekleştirilmiştir. Tüm bunların yanı sıra, bu çalışma ile pullulanın öncü HIPE'lerin sekonder bir sulu ortamda dağıtılarak damlalar halinde polimerleştirilmesinde kararlılığın sağlanması açısından stabilizatör olarak önemli bir görev üstlendiği de ispatlanmıştır.

\section{TEŞEKKÜR}

Çalışmamıza sağladıkları destekten ötürü TÜBİTAK’a (TÜBİTAK Proje No: 113Z465) ve Yalova Üniversitesi Bilimsel Araştırma Projeleri Koordinasyon Birimi’ne (Proje No: 2013/YL/015) teşekkür ederiz

\section{KAYNAKLAR}

[1] Cameron, N. R., \& Sherrington, D. C. (1996). High Internal Phase Emulsions (HIPEs) - Structure, Properties and Use in Polymer Preparation. ss. 163-214. Advances in Polymer Science Book Series (Polymer, Volume 126). Springer-Verlag Berlin Heidelberg 214s.

[2] Cameron, N. R. (2005). High Internal Phase Emulsion Templating as a Route to Well-defined Porous Polymers. Polymer, 46, 1439-1449. 
[3] Silverstein, M. S. (2014). Emulsion-Templated Porous Polymers: A Retrospective Perspective. Polymer, 55 , 304-320.

[4] Silverstein, M. S. (2014). PolyHIPEs: Recent Advances in Emulsion-Templated Porous Polymers. Progress in Polymer Science, 39, 199-234.

[5] Silverstein, M. S. (2017). Emulsion-Templated Polymers: Contemporary Contemplations. Polymer, 126, 261-282.

[6] Barby, D., \& Haq, Z. (1982). Low Density Porous Cross-linked Polymeric Materials and Their Preparation. European Patents 0,060,138 (to Unilever).

[7] Pulko, I., \& Krajnc, P. (2012). High Internal Phase Emulsion Templating - A Path to Hierarchically Porous Functional Polymers. Macromolecular Rapid Communications. 33, 1731-1746.

[8] Zhang, T., Sanguramath, R. A., Israel, S., \& Silverstein, M. S. (2019). Emulsion Templating: Porous Polymers and Beyond. Macromolecules, 52, 5445-5479.

[9] Mert, H. H., Mert, M. S., \& Mert, E. H. (2019). A Statistical Approach for Tailoring the Morphological and Mechanical Properties of Polystyrene PolyHIPEs: Looking through Experimental Design. Materials Research Express, 6 (11) 115306.

[10] Oschatz, M., Borchardt, L., Thommes, M., Cychosz, K. A., Senkovska, I., Klein, N., Frind, R., Leistner, M., Presser, V., Gogotsi, Y., \& Kaskel, S. (2012). Carbide-Derived Carbon Monoliths with Hierarchical Pore Architectures. Angewandte Chemie International Edition, 51, 7577 -7580.

[11] Oschatz, M., Borchardt, L., Senkovska, I., Klein, N., Leistner, M., \& Kaskel, S. (2013). Carbon dioxide Activated Carbide-Derived Carbon Monoliths as High Performance Adsorbents. Carbon, 56, 139-145.

[12] Deshmukh, A. B., Nalawade, A. C., Karbhal, I., Qureshi, M. S., \& Shelke, M. V. (2018). Electrochemical Capacitive Energy Storage in PolyHIPE Derived Nitrogen Enriched Hierarchical Porous Carbon Nanosheets. Carbon, 128, 287-295.

[13] Wakeman, R. J., Bhumgara, Z. G., \& Akay, G. (1998). Ion Exchange Modules Formed from Polyhipe Foam Precursors. Chemical Engineering Journal, 70, 133-141.

[14] Alikhani, M., \& Moghbeli, M. R. (2014). Ion-Exchange PolyHIPE Type Membrane for Removing Nitrate Ions: Preparation, Characterization, Kinetics and Adsorption Studies. Chemical Engineering Journal, 239, 93-104.

[15] Barlık, N., Keskinler, B., Kocakerim, M. M., \& Akay, G. (2015). Surface Modification of Monolithic PolyHIPE Polymers for Anionic Functionality and Their Ion Exchange Behavior. Journal of Applied Polymer Science, 132, 42286-42293.

[16] Mert, E. H., Kaya, M. A., \& Y1ldırım, H. (2012). Preparation and Characterization of Polyester-Glycidyl Methacrylate PolyHIPE Monoliths to Use in Heavy Metal Removal. Design Monomers Polymers, 15, 113126.

[17] Mert, E. H., \& Yıldırım, H. (2014). Porous Functional Poly(unsaturated polyester-co-glycidyl methacrylateco-divinylbenzene) PolyHIPE Beads through w/o/w Multiple Emulsions: Preparation, Characterization and Application. e-Polymers, 14(1), 65-73.

[18] San, N., Mert, E. H., Kaya, D., \& Çira, F. (2016). Adsorption Characteristics, Isotherm and Kinetics of a Novel PolyHIPE/Pullulan Composite For Removing Congo Red Dye. Fresenius Environmental Bulletin, 25 (9), 3635-3645. 
[19] Yüce, E., Mert, E. H., Şen, S., Sayg1, S., \& San, N. (2017). Properties and Applications of Nanoclay Reinforced Open-Porous Polymer Composites. Journal of Applied Polymer Science, 134, 45522-45532.

[20] Kovačič , S., Mazaj, M., Ješelnik, M., Pahovnik, D., Žagar, E., Slugovc, C., \& Logar, N. Z. (2015). Synthesis and Catalytic Performance of Hierarchically Porous MIL-100(Fe)@polyHIPE Hybrid Membranes. Macromolecular Rapid Communications, 36, 1605-1611.

[21] Koler, A., Paljevac, M., Cmager, N., Iskra, J., Kolar, M., \& Krajnc, P. (2017). Poly(4-vinylpyridine) PolyHIPEs as Catalysts for Cycloaddition Click Reaction. Polymer, 126, 402-407.

[22] Yuan, W., Chen, X., Xu, Y., Yan, C., Liu, Y., Lian, W., Zhou Y., \& Li, Z. (2018). Preparation and Recyclable Catalysis Performance of Functional Macroporous PolyHIPE Immobilized with Gold Nanoparticles on its surface, Royal Society of Chemistry Advances, 8, 5912-5919.

[23] Yüce, E., Mert, E. H., Krajnc, P., Parın, F. N., San, N., Kaya, D., \& Yıldırım, H. (2017). Photocatalytic Activity of Titania/Polydicyclopentadiene PolyHIPE Composites. Macromolecular Materials and Engineering, 302 (10), 1700091-1700099.

[24] Ruan, G., Wu, Z., Huang, Y., Wei, M., Su, R., \& Du, F. (2016). An Easily Regenerable Enzyme Reactor Prepared from Polymerized High Internal Phase Emulsions. Biochemical and Biophysical Research Communications, 473, 54-60.

[25] Kimmins S. D., Wyman, P., \& Cameron, N. R. (2014). Amine-functionalization of Glycidyl MethacrylateContaining Emulsion-Templated Porous Polymers and Immobilization of Proteinase $K$ for Biocatalysis. Polymer, 55, 416-425.

[26] Pulko, I., Smrekar, V., Podgornik, A., \& Krajnc, P. (2011). Emulsion Templated Open Porous Membranes for Protein Purification. Journal of Chromatography A, 1218, 2396-2401.

[27] Barbetta, A., Dentini, M., Zannoni, E. M., \& De Stefano, M. E. (2005). Tailoring the Porosity and Morphology of Gelatin-Methacrylate PolyHIPE Scaffolds for Tissue Engineering Applications. Langmuir, 21(26), 12333-12341.

[28] Christenson, E. M., Soofi, W., Holm, J. L., Cameron, N. R., \& Mikos, A. G. (2007). Biodegradable Fumarate-Based PolyHIPEs as Tissue Engineering Scaffolds. Biomacromolecules, 8 (12), 3806-3814.

[29] Mert, H. H. (2020). PolyHIPE Composite Based-form Stable Phase Change Material for Thermal Energy Storage. International Journal of Energy Research, 1-12.

[30] Stefanec, D., \& Krajnc, P. (2005). 4-Vinylbenzyl Chloride Based Porous Spherical Polymer Supports Derived from Water-in-Oil-in-Water Emulsions. Reactive and Functional Polymers, 65 (1-2), 37- 45.

[31] Yüce, E., Parın, F. N., Krajncc, P., Mert, H. H., \& Mert, E. H. (2018). Influence of Titania on the Morphological and Mechanical Properties of 1,3-Butanediol Dimethacrylate based PolyHIPE Composites. Reactive and Functional Polymers, 130, 8-15.

[32] Taylor, K.M.L., Pribyl, P., \& Pribyl, J. G. (2019). PolyHIPEs for Separations and Chemical Transformations: A Review. Solvent Extraction and Ion Exchange, 37 (1), 1 -26.

[33] Fernandes, S. C. M., Sadocco, P., Causio, J., Silvestre, A. J. D., Mondragon, I., \& Freire, C. S. R. (2014). Antimicrobial Pullulan Derivative Prepared by Grafting with 3-Aminopropyltrimethoxysilane: Characterization and Ability to Form Transparent Films. Food Hydrocolloids, 35, 247-252.

[34] Çira F., \& Mert, E. H. (2015). PolyHIPE/Pullulan Composites Derived from Glycidyl Methacrylate and 1,3Butanediol Dimethacrylate-Based High Internal Phase Emulsions. Polymer Engineering and Science, 55, 2636-2642. 